\title{
ACURATE neo: How Is This TAVR Valve Doing to Fit into an Increasingly Crowded Field?
}

\author{
Taishi Okuno ${ }^{1} \cdot$ Jonas Lanz ${ }^{1} \cdot$ Thomas Pilgrim $^{1}$ (D) \\ Published online: 8 August 2020 \\ (C) The Author(s) 2020
}

\begin{abstract}
Purpose of Review Critical appraisal of the available evidence on the self-expanding ACURATE neo transcatheter heart valve (THV) for the treatment of aortic valve disease.

Recent Findings In an investigator-initiated, multicenter, randomized non-inferiority trial with broad inclusion criteria, ACURATE neo failed to meet non-inferiority compared with SAPIEN 3 with regard to a primary composite safety and efficacy endpoint at 30 days. The difference was driven by higher rates of moderate or severe paravalvular regurgitation and higher rates of acute kidney injury. In turn, registry data suggest that the safety and efficacy profile of the ACURATE neo is comparable to that of other commercially available devices. Randomized evidence indicated favorable hemodynamic results with large effective orifice areas and low residual gradients.

Summary The self-expanding ACURATE neo THV is associated with higher rates of residual aortic regurgitation compared to the balloon-expandable SAPIEN 3 THV. The supra-annular design with low residual gradients may be advantageous in patients with small anatomy and mild degree of calcification.
\end{abstract}

Keywords Transcatheter aortic valve replacement, ACURATE neo $\cdot$ Self-expanding $\cdot$ Balloon-expandable $\cdot$ Transcatheter heart valve $\cdot$ SCOPE

\section{Introduction}

Since the introduction of transcatheter aortic valve replacement (TAVR) as an alternative for inoperable patients with severe aortic stenosis [1], advances in treatment strategies and refinement of valve systems have expedited the expansion of TAVR to surgical low-risk patients [2, 3]. Nowadays, TAVR is considered a valuable treatment strategy across the entire spectrum of surgical risk based on robust evidence derived from iterative randomized clinical trials and large-scale real-

This article is part of the Topical Collection on New Therapies for Cardiovascular Disease

Thomas Pilgrim

thomas.pilgrim@insel.ch

Taishi Okuno

taishi.okuno@extern.insel.ch; t.okuno.69@gmail.com

Jonas Lanz

Jonas.Lanz@insel.ch

1 Department of Cardiology, Inselspital, Bern University Hospital, University of Bern, CH-3010 Bern, Switzerland world registries [4]. Strategy trials comparing TAVR to surgical aortic valve replacement (SAVR) have been performed with different generations of transcatheter heart valve (THV) systems of the balloon-expandable SAPIEN series (Edwards Lifesciences, Irvine, CA, USA) and the self-expanding CoreValve/Evolut series (Medtronic, Minneapolis, MN, USA). A number of novel THVs have been introduced with the aim to overcome limitations of these two dominant market players [5••, 6-9]. Among them, the ACURATE neo THV (Boston Scientific, Marlborough, MA, USA) is one of the leading devices, which has a unique valve design and deployment mechanism [5••]. In this review, we summarize the available evidence on this device and elucidate its strengths and weaknesses as compared to other commercially available THV devices.

\section{The ACURATE neo: Device Characteristics and Deployment Mechanism}

The ACURATE neo is composed of porcine pericardial leaflets mounted on a self-expanding nitinol stent frame in supra- 
annular position and is implanted in a top-down two-step release mechanism. This unique deployment mechanism minimizes peri-procedural outflow obstruction and allows for stable positioning without rapid ventricular stimulation. Three stabilization arches and the protruding upper crown further enhance co-axial deployment and device stabilization (Fig. 1). In addition, the upper crown may deter the native leaflets from the coronary ostia and reduce the risk of coronary obstruction (Fig. 1). Currently, three sizes of the THV (S, M, L) are available and accommodate aortic annular diameters ranging from 21 to $27 \mathrm{~mm}$. The delivery system is compatible with an 18-Fr (15-Fr expandable) sheath. Pre-dilatation is required prior to valve implantation according to the instructions for use in order to allow adequate device expansion.

\section{The ACURATE neo Device for Native Aortic Valve Stenosis}

Several studies have investigated the clinical outcomes up to 1 year after implantation of the ACURATE neo THV for treatment of severe aortic stenosis in elderly patients

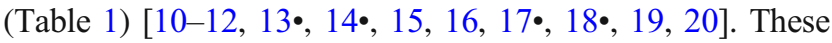
studies have proposed some strengths and drawbacks of ACURATE neo, which may guide how to optimally tailor the device to the most appropriate anatomy.

The top-down two-step deployment mechanism with stabilization arches and an upper crown anchoring the device in the aortic annulus facilitates stable deployment and mitigates the risk of device migration and potentially also coronary obstruction (Fig. 1). Malpositioning occurred in 0.5 to $2.2 \%$ across studies conducted in patients treated for severe stenosis of the native aortic valve [10, $11,15]$. The incidence of coronary obstruction was negligible when the ACURATE neo device was implanted in native tricuspid aortic valves $[10,11,13 \bullet, 15]$. The nitinol frame of the ACURATE neo THV has a lower radial force as compared to other self-expanding THVs (Fig.
1), thus requiring pre-dilatation and increasing the need for post-dilatation [5••]. The lower radial force may lead to less mechanical injury to the conduction system (Fig. 1) and explain the relatively low need for a new permanent pacemaker ranging from 8.3 to $12.3 \%$ [10-12, 13•, $15,16,17 \cdot]$, which is considerably lower than reported pacemaker rates of other self-expanding THVs (17.4 to $34.1 \%$ ) [3, 21]. Evidence from a small multicenter study suggested that the rate of new permanent pacemakers can be reduced to $2.3 \%$ when applying a minimizing trauma strategy using a smaller balloon for pre- and post-dilation [12]. On the downside, the lower radial force may translate into malappositioning of the device to the aortic annulus and increase the risk of paravalvular regurgitation despite the presence of an outer skirt (Fig. 1). In a randomized trial among 739 patients from 20 centers, the occurrence of valve-related dysfunction, mainly moderate or severe aortic regurgitation, at 30 days, was significantly higher among patients treated with ACURATE neo (9\%) compared to Edwards SAPIEN $3(3 \%)$ $(P<0.0001)[5 \bullet \cdot$. In contrast, site-reported incidence of relevant paravalvular regurgitation (moderate to severe) in observational studies was considerably lower, ranging from 1.4 to $4.8 \%[10-12,13 \bullet, 14 \bullet, 15,16]$. The supraannular design of the THV achieves a larger effective orifice area (EOA) with lower transprosthetic gradients, and potentially prevents prosthesis-patient mismatch (Fig. 1) [22]. Across the studies, EOA and mean transprosthetic gradients ranged from 1.6 to $2.0 \mathrm{~cm}^{2}$ and from 6.9 to $10.6 \mathrm{mmHg}$ (mean or median), respectively $[10-12,13 \bullet, 14 \bullet, 15,16,17 \bullet]$. In a propensity-scorematched comparison in patients with a small aortic annulus (area $<400 \mathrm{~mm}^{2}$ ), the ACURATE neo THV was associated with a significantly lower incidence of prosthesispatient mismatch as compared with the SAPIEN 3 THV [23]. Finally, 30-day mortality was reported as 0.6 to $3.4 \%$, which were comparable to the results of TAVR randomized clinical trials $[10-12,13 \bullet, 14 \bullet, 15,16,17 \bullet]$.
Fig. 1 Unique design of the ACURATE neo transcatheter heart valve. Overview of the unique features of the device and their clinical relevance are presented. (Image/content provided courtesy of Boston Scientific. (C) 2020 Boston Scientific Corporation or its affiliates. All rights reserved)

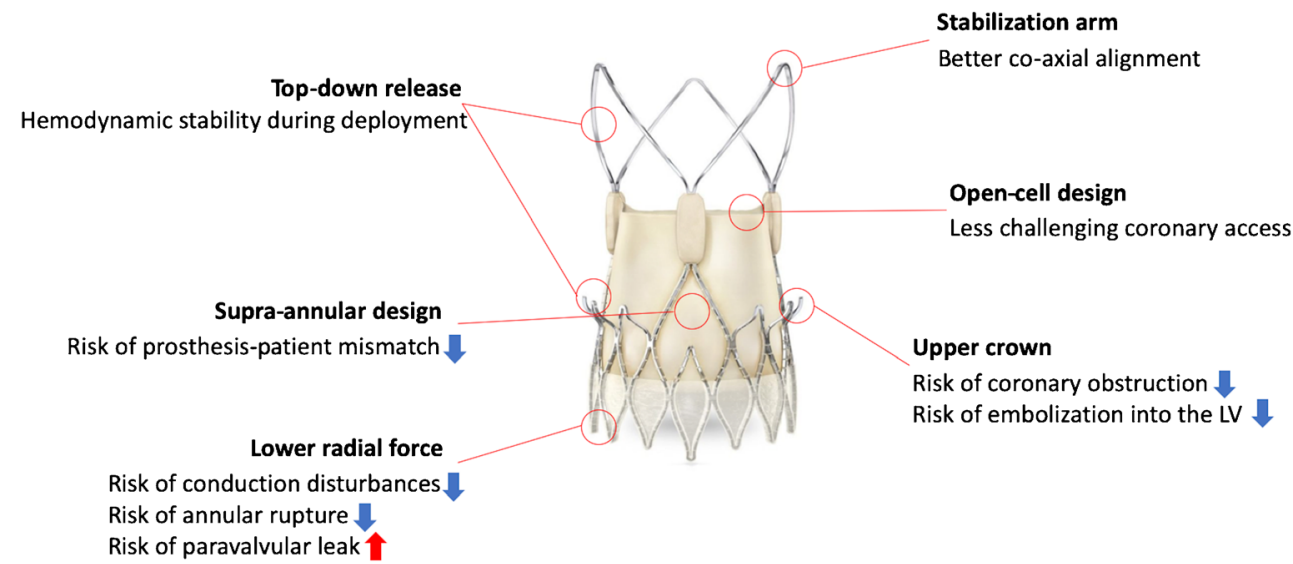




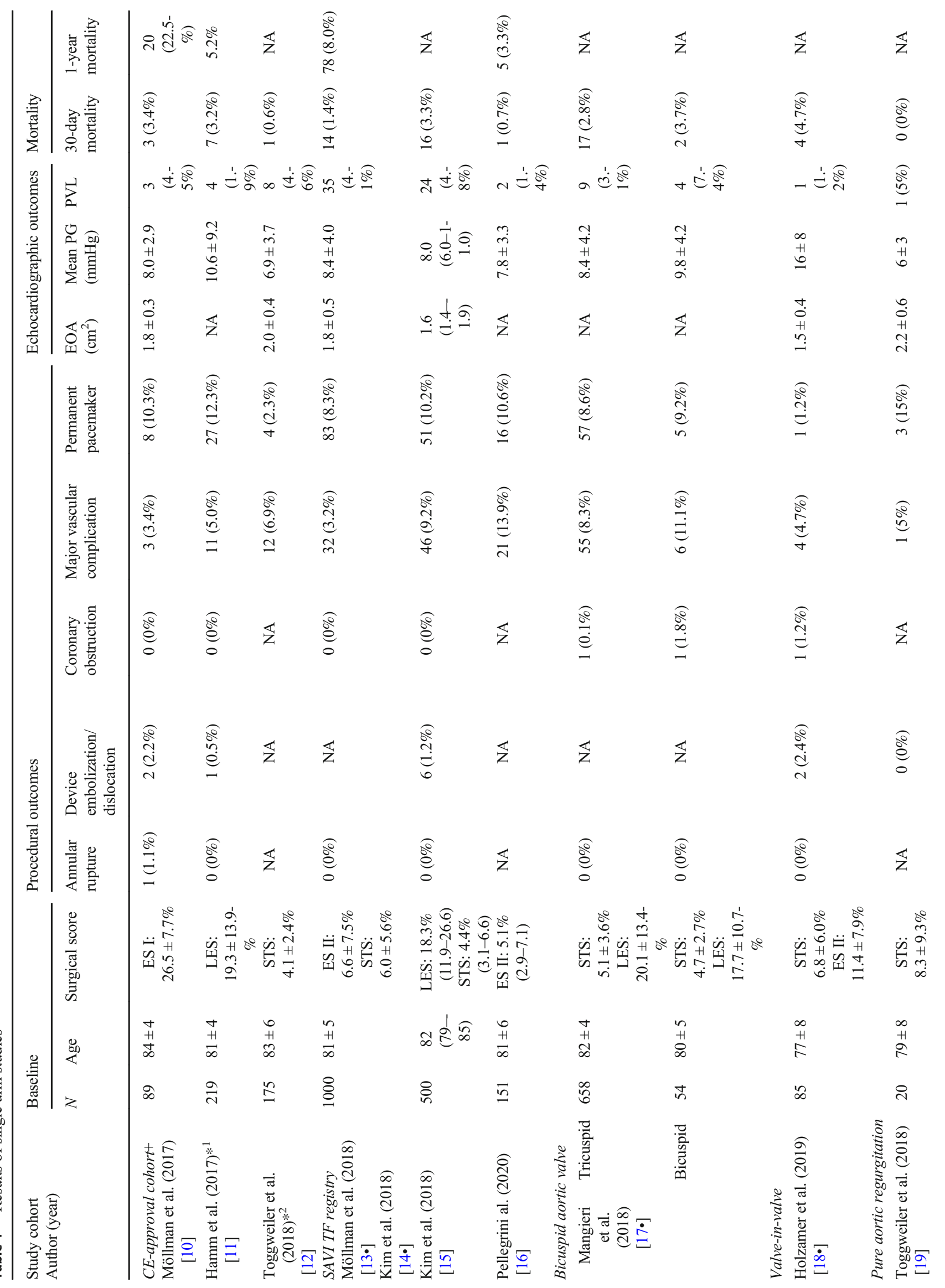




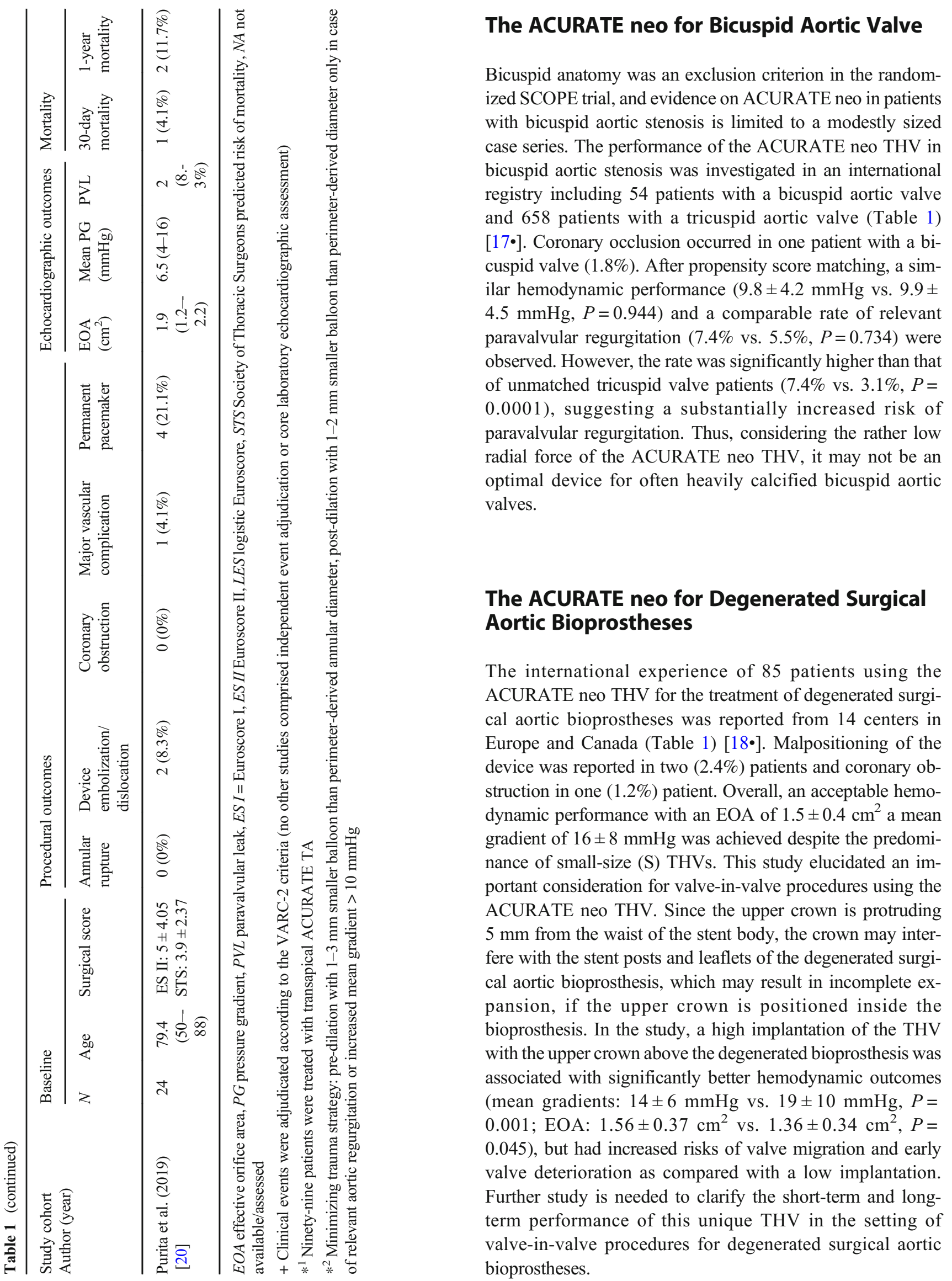




\section{The ACURATE neo THV for Native Pure Aortic Valve Regurgitation}

TAVR is an alternative to SAVR for inoperable patients with aortic regurgitation. The off-label use of the ACURATE neo THV in patients with native pure aortic regurgitation is limited to small case series $[19,20]$. Native pure aortic regurgitation is frequently characterized by the absence of annular and leaflet calcification, which complicates THV anchoring and increases the risk of device migration. The increased stroke volume secondary to aortic regurgitation and the presence of aortic root dilation render accurate device positioning difficult and may further increase the risk of device migration [24]. In this context, the ACURATE neo THV may have notable advantages owing to its unique $\mathrm{x}$-shaped design and the deployment system (Fig. 1). In the absence of calcification, the protruding upper crown may serve as a safety anchor to prevent its dislocation into the left ventricular outflow tract (LVOT). Furthermore, the stable top-down two-step deployment system may be less affected by the increased stroke volume and facilitate the accurate positioning of the THV. Currently, two small multicenter experiences of the ACURATE neo THV for native pure aortic regurgitation have been published (Table 1) $[19,20]$. In the first series of 20 patients, rapid pacing was used during THV implantation in $70 \%$ of the patients [19]. In one case (5\%), a second THV implantation was required due to a low positioning of the initial THV. In contrast, in the second series of 24 cases, rapid pacing was used in $20 \%$ of cases only, and a second THV implantation was required in three cases $(12.5 \%)$, in one case for severe paravalvular regurgitation $(4.1 \%)$, and in two cases for device migration (8.3\%) [20]. In the two case series, relevant paravalvular regurgitation was observed in one (5\%) and two $(8.3 \%)$ patients, respectively $[19,20]$. Mean THV oversizing was close to $10 \%$ and resulted in new pacemaker implantation rates of $15 \%$ and $21 \%$, respectively $[19,20]$. In summary, transfemoral TAVR with the ACURATE neo THV may be an option for the treatment of pure aortic regurgitation in selected inoperable patients with suitable anatomy.

\section{Comparison with Other Contemporary Devices}

Balloon-expandable THVs from the SAPIEN family and selfexpanding THVs from the CoreValve/Evolut family have been extensively tested in randomized clinical trials and represent the benchmark for new devices [4]. The ACURATE neo THV has been compared to the balloon-expanding Edwards SAPIEN 3 THV in one randomized controlled trial and six propensity-score-matched studies $[5 \cdot, 23-30]$ (Table 2).
The SCOPE I trial was a randomized non-inferiority trial comparing ACURATE neo versus SAPIEN 3 in 739 patients with severe aortic stenosis with regard to a primary composite safety and efficacy endpoint at 30 days. TAVR with ACURATE neo failed to meet non-inferiority compared to SAPIEN 3 with respect to the composite of allcause death, any stroke, life-threatening or disabling bleeding, major vascular complications, coronary artery obstruction, acute kidney injury (stage 2 or 3), rehospitalization for valve-related symptoms or congestive heart failure, valve-related dysfunction requiring repeat procedure, moderate or severe prosthetic valve regurgitation, or prosthetic valve stenosis within 30 days of the procedure [5*•]. The difference was largely driven by a higher rate of moderate or severe paravalvular regurgitation in patients treated with ACURATE neo compared to SAPIEN 3 (9\% vs. 3\%, $P<0.0001)$. In turn, the transvalvular gradient was lower and the mean effective orifice area larger in patients treated with ACURATE neo compared with SAPIEN 3.

A low incidence of atrioventricular conductance disturbances requiring permanent pacemaker implantation compared not only to self-expanding but also to balloonexpandable devices has been considered an important strength of the unique design of the ACURATE neo THV. While retrospective cohort studies have shown a significantly lower rate of permanent pacemaker implantation in patients treated with ACURATE neo compared with SAPIEN 3 [24, 26, 27], findings from the SCOPE I trial indicate comparable rates of permanent pacemaker implantation ( $10 \% \mathrm{vs}$. $9 \%, P=0.76$ ) [5••]. Interestingly, a multicenter study including only patients with pre-existing right bundle branch block demonstrated a significantly lower incidence of new pacemaker implantation in the ACURATE neo THV as compared to the SAPIEN 3 THV (23.1\% vs. $44.6 \%, P=0.016)$ [26]. The SCOPE I trial also suggested an increased risk of acute kidney injury following TAVR in the ACURATE neo THV, which may be attributable to increased contrast volume associated with the longer procedural time due to more frequent pre- and post-dilation [5••]. Although the difference was not observed in other retrospective studies, rates of pre- and postdilation were consistently higher in the ACURATE neo THV [23-27], and some studies showed larger contrast volume and longer procedural time as compared to the SAPIEN 3 THV $[25,28]$.

A randomized clinical trial comparing the ACURATE neo THV versus the Evolut R/PRO THV has recently completed patient enrollment, and the results will soon be available (NCT03192813). A propensity-score-matched comparison suggested comparable short-term outcomes, including device success, relevant paravalvular regurgitation, all-cause death, stroke, new permanent pacemaker, and early safety endpoint, between the two self-expanding THVs (Table 2) [29•]. Data on long-term valve durability is missing at this stage. 
Table 2 Results of comparison studies of ACURATE neo with SAPIEN 3 and Evolut R/PRO

\begin{tabular}{|c|c|c|c|c|c|c|c|c|}
\hline \multirow{2}{*}{$\begin{array}{l}\text { Study design } \\
\text { Author (year) }\end{array}$} & \multicolumn{3}{|c|}{ Baseline of ACURATE-arm } & \multicolumn{2}{|l|}{ Valve performance } & \multicolumn{3}{|l|}{ Clinical outcome } \\
\hline & $N$ & Age & Surgical score & Hemodynamic results & PVL & $\begin{array}{l}\text { Pacemaker } \\
\text { implantation }\end{array}$ & AKI stage 2 or 3 & $\begin{array}{l}\text { 30-day } \\
\text { mortality }\end{array}$ \\
\hline \multicolumn{9}{|l|}{ Versus SAPIEN 3} \\
\hline $\begin{array}{l}\text { PS-matched } \\
\quad \text { comparison } \\
\text { Husser et al. (2017) } \\
{[25]}\end{array}$ & 311 & $81 \pm 6$ & LES: $18 \pm 10 \%$ & $\begin{array}{l}9 \pm 5 \text { vs. } 13 \pm 5 \mathrm{mmHg} \\
(P<0.001)\end{array}$ & $\begin{array}{l}4.8 \% \text { vs. } 1.8 \% \\
(P=0.008)\end{array}$ & $\begin{array}{l}10.2 \% \text { vs. } 16.4 \% \\
(P=0.018)\end{array}$ & $\begin{array}{l}3.2 \% \text { vs. } 2.7 \% \\
(P=0.679)\end{array}$ & $\begin{array}{l}2.3 \% \text { vs. } \\
1.9 \% \\
(P=0.742)\end{array}$ \\
\hline $\begin{array}{l}\text { PS-matched } \\
\text { comparison }^{* 1} \\
\text { Mauri et al. (2017) } \\
{[23]}\end{array}$ & 92 & $83 \pm 7$ & $\begin{array}{l}\text { LES: } \\
\qquad 16.2 \pm 8.8 \%\end{array}$ & $\begin{array}{l}9.3 \pm 3.9 \text { vs. } 14.5 \pm 5.5 \mathrm{mmHg} \\
(P<0.001)\end{array}$ & $\begin{array}{l}4.5 \% \text { vs. } 3.6 \% \\
(P=0.208)\end{array}$ & $\begin{array}{l}12.0 \% \text { vs. } 15.2 \% \\
(P=0.678)\end{array}$ & NA & $\begin{array}{l}1.1 \% \text { vs. } \\
2.2 \% \\
(P=1.000)\end{array}$ \\
\hline $\begin{array}{l}\text { PS-matched } \\
\text { comparison } \\
\text { Schaefer et al. } \\
\quad(2017) \\
{[26]}\end{array}$ & 104 & $82 \pm 6$ & $\begin{array}{l}\text { LES: } \\
\quad 15.9 \pm 9.3 \% \\
\text { STS: } \\
5.8 \pm 3.8 \%\end{array}$ & $\begin{array}{l}7.3 \pm 2.8 \text { vs. } 11.8 \pm 3.5 \mathrm{mmHg} \\
(P<0.001)\end{array}$ & $\begin{array}{l}4.8 \% \text { vs. } 1.9 \% \\
(P=0.257)\end{array}$ & $\begin{array}{l}10.6 \% \text { vs. } 16.4 \% \\
(P=0.239)\end{array}$ & $\begin{array}{l}2.9 \% \text { vs. } 1.9 \% \\
(P=0.655)\end{array}$ & $\begin{array}{l}3.9 \% \text { vs. } \\
0.9 \% \\
(P=0.317)\end{array}$ \\
\hline $\begin{array}{l}\text { PS-matched } \\
\quad \text { comparison }^{2} \\
\text { Husser et al. (2019) } \\
{[27]}\end{array}$ & 65 & $\begin{array}{l}81 \\
(77-84)\end{array}$ & $\begin{array}{l}\text { LES: } 14.3 \% \\
\quad(9.8-21.5)\end{array}$ & $\begin{array}{l}\text { 7(5-10) vs. } 11(9-12,13 \cdot, 14 \bullet) \\
\quad \mathrm{mmHg} \\
(P<0.001)\end{array}$ & $\begin{array}{l}4.6 \% \text { vs. } 0 \% \\
(P=0.244)\end{array}$ & $\begin{array}{l}23.1 \% \text { vs. } 44.6 \% \\
(P=0.016)\end{array}$ & $\begin{array}{l}1.5 \% \text { vs. } 7.7 \% \\
(P=0.208)\end{array}$ & $\begin{array}{l}3.1 \% \text { vs. } \\
\quad 6.2 \% \\
(P=0.680)\end{array}$ \\
\hline $\begin{array}{l}\text { PS-matched } \\
\text { comparison } \\
\text { Barth et al. (2019) } \\
{[28]}\end{array}$ & 329 & $81 \pm 5$ & $\begin{array}{l}\text { LES: } \\
\qquad 18.8 \pm 14.7 \%\end{array}$ & $\begin{array}{l}8.6 \pm 4.6 \text { vs. } 10.9 \pm 4.2 \mathrm{mmHg} \\
(P<0.001)\end{array}$ & $\begin{array}{l}12.0 \% \text { vs. } \\
3.1 \% \\
(P<0.001)\end{array}$ & $\begin{array}{l}11.9 \% \text { vs. } 18.5 \% \\
(P=0.020)\end{array}$ & NA & $\begin{array}{l}4.6 \% \text { vs. } \\
2.1 \% \\
(P=0.134)\end{array}$ \\
\hline $\begin{array}{l}\text { Randomized } \\
\quad \text { clinical trial }+ \\
\text { Lanz et al. (2019) } \\
{[5 \bullet \bullet} \\
\text { Versus Evolut PRO }\end{array}$ & 372 & $83 \pm 4$ & $\begin{array}{l}\text { STS: } 3.7 \% \\
(2.5-4.9)\end{array}$ & $\begin{array}{l}7(1-15) \text { vs. } 11(2-23) \mathrm{mmHg} \\
(P<0.0001)\end{array}$ & $\begin{array}{l}9.4 \% \text { vs. } 2.8 \% \\
(P<0.0001)\end{array}$ & $\begin{array}{l}10 \% \text { vs. } 9 \% \\
(P=0.76)\end{array}$ & $\begin{array}{l}3 \% \text { vs. } 1 \% \\
(P=0.0340)\end{array}$ & $\begin{array}{l}2 \% \text { vs. } 1 \% \\
(P=0.09)\end{array}$ \\
\hline $\begin{array}{l}\text { PS-matched } \\
\text { comparison } \\
\text { Pagnesi et al. } \\
(2019) \\
{[29 \bullet[}\end{array}$ & 251 & $81 \pm 7$ & $\begin{array}{l}\text { ES II: } \\
\quad 6.34 \pm 5.21 \% \\
\text { STS: } \\
\quad 5.08 \pm 3.05 \%\end{array}$ & $\begin{array}{l}8.3 \pm 4.0 \text { vs. } 7.3 \pm 3.6 \mathrm{mmHg} \\
(P=0.003)\end{array}$ & $\begin{array}{l}7.3 \% \text { vs. } 5.7 \% \\
(P=0.584)\end{array}$ & $\begin{array}{l}11.0 \% \text { vs. } 12.8 \% \\
(P=0.565)\end{array}$ & $\begin{array}{l}2.4 \% \text { vs. } 1.6 \% \\
(P=0.543)\end{array}$ & $\begin{array}{l}3.2 \% \text { vs. } \\
1.2 \% \\
(P=0.221)\end{array}$ \\
\hline Versus SAPIEN 3 ve & rsus $E$ & Evolut $R$ & & & & & & \\
\hline $\begin{array}{l}\text { PS-matched } \\
\quad \text { comparison } \\
\text { Costa et al. }(2020) \\
{[30]}\end{array}$ & 48 & $\begin{array}{l}82 \\
(80-- \\
85)\end{array}$ & STS: $4.0 \pm 3.3 \%$ & $\begin{array}{l}8.4 \pm 3.5 \text { vs. } 9.7 \pm 7.5 \text { vs. } \\
\quad 6.1 \pm 2.4 \mathrm{mmHg} \\
(P<0.001)\end{array}$ & $\begin{array}{l}0 \% \text { vs. } 0 \% \text { vs. } \\
\quad 2.1 \% \\
(P<0.01)\end{array}$ & $\begin{array}{l}2.1 \% \text { vs. } 8.3 \% \text { vs. } \\
\quad 16.7 \% \\
(P=0.046)\end{array}$ & $\begin{array}{l}1.0 \% \text { vs. } 2.2 \% \\
\text { vs. } 2.7 \% \\
(P=0.659)\end{array}$ & $\begin{array}{l}0 \% \text { vs. } 0 \% \\
\text { vs. } 0 \% \\
(P=\mathrm{NA})\end{array}$ \\
\hline
\end{tabular}

PS propensity score, $P V L$ paravalvular leak, ES II Euroscore II, LES logistic Euroscore, STS Society of Thoracic Surgeons predicted risk of mortality, NA not available/assessed

+ Independent event adjudication and echocardiographic core laboratory assessment were applied (no other studies comprised independent event adjudication or core laboratory echocardiographic assessment)

$*^{1}$ Selective cohort with an aortic annulus area $<400 \mathrm{~mm}^{2}$

$*^{2}$ Selective cohort with pre-existent right bundle branch block and no pacemaker at baseline

\section{Place for the ACURATE neo THV}

The ACURATE neo THV may not be the optimal device for patients with excessive leaflet calcification and LVOT calcification, in which an increased risk of paravalvular regurgitation following TAVR is anticipated [31-34]. However, some specific patient groups may benefit from the unique design of the ACURATE neo THV.

\section{Patients at High Risk of Conduction Disturbances}

A low risk of permanent pacemaker implantation compared with other self-expanding devices makes ACURATE neo a valuable device in patients with preexisting conduction disturbances, i.e., right bundle branch block, and may facilitate early discharge following TAVR [27, 35]. 


\section{Patients at High Risk of Coronary Obstruction or Future Coronary Re-access}

Conceptually, the THV may mitigate the risk of coronary obstruction in patients with low coronary distance, small sinus of Valsalva, and long leaflets [36, 37]. Furthermore, coronary re-access may be less challenging as compared to the other THVs because of the short stent body and the open-cell design of the upper crown. Patients with coronary artery disease at risk of future percutaneous coronary interventions may be suitable candidates for this THV [38-40].

\section{Patients at High Risk of Prosthesis-Patient Mismatch}

The ACURATE neo valve may be useful in patients with a small anatomy that my benefit from the supra-annular design to reduce the risk of prosthesis-patient mismatch [22].

\section{Patients with Horizontal Aorta}

Increased aortic root angulation has been shown to adversely influence acute procedural success following other selfexpanding THV (CoreValve) possibly due to its long stent frame and less flexible delivery system [41]. Therefore, the short stent frame and the flexible delivery system of the ACURATE neo may be advantageous in these situations. The unique stabilization arches may also provide a better coaxial alignment and facilitate accurate deployment.

\section{Conclusions}

The ACURATE neo THV conceptually differs from other self-expanding valves with a two-step top-down release mechanism. Low radial strength reduces the need for permanent pacemaker implantation and comes at the expense of an increased risk of paravalvular aortic regurgitation compared to the SAPIEN 3 THV. Data on long-term outcomes and valve durability is missing.

Funding Information Open access funding provided by University of Bern.

\section{Compliance with Ethical Standards}

Conflict of Interest Dr. Pilgrim reports research grants to the institution from Boston Scientific and Biotronik, and personal fees from Biotronik, Boston Scientific, and HighLife SAS. Dr. Okuno reports speaker fees from Abbott. All other authors have no relationships relevant to the contents of this article to disclose.
Human and Animal Rights and Informed Consent This article does not contain any studies with human or animal subjects performed by any of the authors.

Open Access This article is licensed under a Creative Commons Attribution 4.0 International License, which permits use, sharing, adaptation, distribution and reproduction in any medium or format, as long as you give appropriate credit to the original author(s) and the source, provide a link to the Creative Commons licence, and indicate if changes were made. The images or other third party material in this article are included in the article's Creative Commons licence, unless indicated otherwise in a credit line to the material. If material is not included in the article's Creative Commons licence and your intended use is not permitted by statutory regulation or exceeds the permitted use, you will need to obtain permission directly from the copyright holder. To view a copy of this licence, visit http://creativecommons.org/licenses/by/4.0/.

\section{References}

Papers of particular interest, published recently, have been highlighted as:

- Of importance

•. Of major importance

1. Leon MB, Smith CR, Mack M, Miller DC, Moses JW, Svensson LG, et al. Transcatheter aortic-valve implantation for aortic stenosis in patients who cannot undergo surgery. N Engl J Med. 2010;363(17):1597-607.

2. Mack MJ, Leon MB, Thourani VH, Makkar R, Kodali SK, Russo $\mathrm{M}$, et al. Transcatheter aortic-valve replacement with a balloonexpandable valve in low-risk patients. N Engl J Med. 2019;380(18):1695-705.

3. Popma JJ, Deeb GM, Yakubov SJ, Mumtaz M, Gada H, O'Hair D, et al. Transcatheter aortic-valve replacement with a self-expanding valve in low-risk patients. N Engl J Med. 2019;380(18):1706-15.

4. Siontis GCM, Overtchouk P, Cahill TJ, Modine T, Prendergast B, Praz F, et al. Transcatheter aortic valve implantation vs. surgical aortic valve replacement for treatment of symptomatic severe aortic stenosis: an updated meta-analysis. Eur Heart J. 2019;40(38):314353.

5.• Lanz J, Kim WK, Walther T, Burgdorf C, Mollmann H, Linke A, et al. Safety and efficacy of a self-expanding versus a balloonexpandable bioprosthesis for transcatheter aortic valve replacement in patients with symptomatic severe aortic stenosis: a randomised non-inferiority trial. Lancet (London, England). 2019;394(10209): 1619-28 This is the first randomized clinical trial comparing the self-expanding ACURATE neo to the balloon-expandable SAPIEN 3 transcatheter heart valve. ACURATE neo failed to meet non-inferiority compared with SAPIEN 3 with regards to a primary composite safety and efficacy endpoint at $\mathbf{3 0}$ days.

6. Sondergaard L, Rodes-Cabau J, Hans-Peter Linke A, Fichtlscherer S, Schafer U, Kuck KH, et al. Transcatheter aortic valve replacement with a repositionable self-expanding prosthesis: the PORTICO-I trial 1-year outcomes. J Am Coll Cardiol. 2018;72(23 Pt A):2859-67.

7. Barker CM, Reardon MJ. Transcatheter aortic valve replacement with the lotus valve system. Futur Cardiol. 2018;14(5):367-73. 
8. Cuevas O, Moreno R, Pascual-Tejerina V, Toggweiler S, Brinkert $\mathrm{M}, \mathrm{Baz} \mathrm{J}$, et al. The Allegra transcatheter heart valve: European multicentre experience with a novel self-expanding transcatheter aortic valve. EuroIntervention. 2019;15(1):71-3.

9. Tchetche D, Windecker S, Kasel AM, Schaefer U, Worthley S, Linke A, et al. 1-year outcomes of the CENTERA-EU trial assessing a novel self-expanding transcatheter heart valve. JACC Cardiovasc Interv. 2019;12(7):673-80.

10. Mollmann H, Walther T, Siqueira D, Diemert P, Treede H, Grube E, et al. Transfemoral TAVI using the self-expanding ACURATE neo prosthesis: one-year outcomes of the multicentre "CE-approval cohort". EuroIntervention. 2017;13(9):e1040-e6.

11. Hamm K, Reents W, Zacher M, Kerber S, Diegeler A, Schieffer B, et al. Transcatheter aortic valve implantation using the ACURATE TA and ACURATE neo valves: a four-year single-centre experience. EuroIntervention. 2017;13(1):53-9.

12. Toggweiler S, Nissen H, Mogensen B, Cuculi F, Fallesen C, Veien KT, et al. Very low pacemaker rate following ACURATE neo transcatheter heart valve implantation. EuroIntervention. 2017;13(11):1273-80.

13. Mollmann H, Hengstenberg C, Hilker M, Kerber S, Schafer U, Rudolph T, et al. Real-world experience using the ACURATE neo prosthesis: 30 -day outcomes of 1,000 patients enrolled in the SAVI TF registry. EuroIntervention. 2018;13(15):e1764-e70 This study reports 30-day clinical outcomes of ACURATE neo from the largest real-world registry (SAVI TF) to date.

14. Kim WK, Hengstenberg C, Hilker M, Kerber S, Schafer U, Rudolph T, et al. The SAVI-TF Registry: 1-year outcomes of the European post-market registry using the ACURATE neo transcatheter heart valve under real-world conditions in 1,000 patients. JACC Cardiovasc Interv. 2018;11(14):1368-74 This study reports 1-year clinical outcomes of ACURATE neo from the largest real world registry (SAVI TF) to date.

15. Kim WK, Mollmann H, Liebetrau C, Renker M, Rolf A, Simon P, et al. The ACURATE neo transcatheter heart valve: a comprehensive analysis of predictors of procedural outcome. JACC Cardiovasc Interv. 2018;11(17):1721-9.

16. Pellegrini C, Rheude T, Trenkwalder T, Mayr NP, Michel J, Kastrati A, et al. One-year clinical outcome with a novel selfexpanding transcatheter heart valve. Catheter Cardiovasc Interv. 2019;94(6):783-92.

17. Mangieri A, Chieffo A, Kim WK, Stefanini GG, Rescigno G, Barbanti M, et al. Transcatheter aortic valve implantation using the ACURATE neo in bicuspid and tricuspid aortic valve stenosis: a propensity-matched analysis of a European experience. EuroIntervention. 2018;14(12):e1269-e75 This international registry included 54 patients with a bicuspid aortic valve who were treated with ACURATE neo. While a similar rate of relevant paravalvular regurgitation was observed as compared to propensity-score-matched tricuspid valve patients, the rate was significantly higher than that of unmatched tricuspid valve patients.

18. Holzamer A, Kim WK, Ruck A, Sathananthan J, Keller L, Cosma J, et al. Valve-in-valve implantation using the ACURATE neo in degenerated aortic bioprostheses: an international multicenter analysis. JACC Cardiovasc Interv. 2019;12(22):2309-16 This study reports the international experience of 85 patients using the ACURATE neo THV for the treatment of degenerated surgical aortic bioprostheses.

19. Toggweiler S, Cerillo AG, Kim WK, Biaggi P, Lloyd C, Hilker M, et al. Transfemoral implantation of the Acurate neo for the treatment of aortic regurgitation. J Invasive Cardiol. 2018;30(9):329-33.

20. Purita PAM, Tahoces LS, Fraccaro C, Nai Fovino L, Kim WK, Espada-Guerreiro C, et al. Transcatheter treatment of native aortic valve regurgitation: results from an international registry using the transfemoral ACURATE neo valve. Int J Cardiol Heart Vasc. 2020;27:100480.

21. Thyregod HG, Steinbruchel DA, Ihlemann N, Nissen H, Kjeldsen BJ, Petursson $\mathrm{P}$, et al. Transcatheter versus surgical aortic valve replacement in patients with severe aortic valve stenosis: 1-year results from the all-comers NOTION randomized clinical trial. J Am Coll Cardiol. 2015;65(20):2184-94.

22. Okuno T, Khan F, Asami M, Praz F, Heg D, Winkel MG, et al. Prosthesis-patient mismatch following transcatheter aortic valve replacement with supra-annular and intra-annular prostheses. JACC Cardiovasc Interv. 2019.

23. Mauri V, Kim WK, Abumayyaleh M, Walther T, Moellmann H, Schaefer U, et al. Short-term outcome and hemodynamic performance of next-generation self-expanding versus balloonexpandable transcatheter aortic valves in patients with small aortic annulus: a multicenter propensity-matched comparison. Circ Cardiovasc Interv. 2017;10(10).

24. Franzone A, Piccolo R, Siontis GC, Lanz J, Stortecky S, Praz F, et al. Transcatheter aortic valve replacement for the treatment of pure native aortic valve regurgitation: a systematic review. JACC Cardiovasc Interv. 2016;9(22):2308-17.

25. Husser O, Kim WK, Pellegrini C, Holzamer A, Walther T, Mayr $\mathrm{PN}$, et al. Multicenter comparison of novel self-expanding versus balloon-expandable transcatheter heart valves. JACC Cardiovasc Interv. 2017;10(20):2078-87.

26. Schaefer A, Linder M, Seiffert M, Schoen G, Deuschl F, Schofer N, et al. Comparison of latest generation transfemoral self-expandable and balloon-expandable transcatheter heart valves. Interact Cardiovasc Thorac Surg. 2017;25(6):905-11.

27. Husser O, Pellegrini C, Kim WK, Holzamer A, Pilgrim T, Toggweiler S, et al. Transcatheter valve selection in patients with right bundle branch block and impact on pacemaker implantations. JACC Cardiovasc Interv. 2019;12(18):1781-93.

28. Barth S, Reents W, Zacher M, Kerber S, Diegeler A, Schieffer B, et al. Multicentre propensity-matched comparison of transcatheter aortic valve implantation using the ACURATE TA/neo selfexpanding versus the SAPIEN 3 balloon-expandable prosthesis. EuroIntervention. 2019;15(10):884-91.

29. Pagnesi M, Kim WK, Conradi L, Barbanti M, Stefanini GG, Zeus $\mathrm{T}$, et al. Transcatheter aortic valve replacement with nextgeneration self-expanding devices: a multicenter, retrospective, propensity-matched comparison of Evolut PRO versus Acurate neo transcatheter heart valves. JACC Cardiovasc Interv. 2019;12(5):433-43 This study suggested comparable shortterm clinical outcomes between propensity-score matched patients treated with the ACURATE neo and the Evolut R/PRO THVs.

30. Costa G, Buccheri S, Barbanti M, Picci A, Todaro D, Di Simone E, et al. Outcomes of three different new generation transcatheter aortic valve prostheses. Catheter Cardiovasc Interv. 2020;95(3):398407.

31. Seiffert M, Fujita B, Avanesov M, Lunau C, Schon G, Conradi L, et al. Device landing zone calcification and its impact on residual regurgitation after transcatheter aortic valve implantation with different devices. Eur Heart J Cardiovasc Imaging. 2016;17(5):57684.

32. Jilaihawi H, Makkar RR, Kashif M, Okuyama K, Chakravarty T, Shiota $\mathrm{T}$, et al. A revised methodology for aortic-valvar complex calcium quantification for transcatheter aortic valve implantation. Eur Heart J Cardiovasc Imaging. 2014;15(12):1324-32.

33. Khalique OK, Hahn RT, Gada H, Nazif TM, Vahl TP, George I, et al. Quantity and location of aortic valve complex calcification predicts severity and location of paravalvular regurgitation and frequency of post-dilation after balloon-expandable transcatheter aortic valve replacement. JACC Cardiovasc Interv. 2014;7(8):885-94. 
34. Okuno T, Asami M, Heg D, Lanz J, Praz F, Hagemeyer D, et al. Impact of left ventricular outflow tract calcification on procedural outcomes after transcatheter aortic valve replacement. J Am Coll Cardiol Intv. 2020; (In press).

35. Moriyama N, Vento A, Laine M. Safety of next-day discharge after transfemoral transcatheter aortic valve replacement with a selfexpandable versus balloon-expandable valve prosthesis. Circ Cardiovasc Interv. 2019;12(6):e007756.

36. Ribeiro HB, Webb JG, Makkar RR, Cohen MG, Kapadia SR, Kodali $\mathrm{S}$, et al. Predictive factors, management, and clinical outcomes of coronary obstruction following transcatheter aortic valve implantation: insights from a large multicenter registry. J Am Coll Cardiol. 2013;62(17):1552-62.

37. Ribeiro HB, Nombela-Franco L, Urena M, Mok M, Pasian S, Doyle D, et al. Coronary obstruction following transcatheter aortic valve implantation: a systematic review. JACC Cardiovasc Interv. 2013;6(5):452-61.
38. Yudi MB, Sharma SK, Tang GHL, Kini A. Coronary angiography and percutaneous coronary intervention after transcatheter aortic valve replacement. J Am Coll Cardiol. 2018;71:1360-78.

39. Ochiai T, Chakravarty T, Yoon SH, Kaewkes D, Flint N, Patel V, et al. Coronary access after TAVR. JACC Cardiovasc Interv. 2020;13(6):693-705.

40. Abdelghani M, Landt M, Traboulsi H, Becker B, Richardt G. Coronary access after TAVR with a self-expanding bioprosthesis: insights from computed tomography. JACC Cardiovasc Interv. 2020;13(6):709-22.

41. Abramowitz Y, Maeno Y, Chakravarty T, Kazuno Y, Takahashi N, Kawamori $\mathrm{H}$, et al. Aortic angulation attenuates procedural success following self-expandable but not balloon-expandable TAVR. J Am Coll Cardiol Img. 2016;9(8):964-72.

Publisher's Note Springer Nature remains neutral with regard to jurisdictional claims in published maps and institutional affiliations. 